\title{
Implementation of new spatial tools for integrated urban development plans in small and medium cities
}

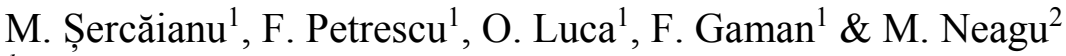 \\ ${ }^{1}$ Urban Engineering and Regional Development, \\ Technical University of Civil Engineering Bucharest, Romania \\ ${ }^{2} \mathrm{Mkbt}$, Romania
}

\begin{abstract}
This paper describes the need and importance of new spatial tools for integrated urban development plans or local developing strategies in small and medium cities based on public information. Due to complexity analyses and the high amount of data available at the public authorities' level, a prior selection and classification of relevant data needs to be carried out, in order to respect processing requirements of spatial tools. In current situations identified in the field of local administration structures from Romania, the relevant data is sometimes misinterpreted or, in some cases, unused if based on unilateral decisions and spatial invalidations. Furthermore, different sources of information, such as urban growth estimation data, need to be integrated in a spatial manner according to theoretical and practical estimations. In order to exemplify benefits for integrated urban development plans or developing strategies, spatial tools were used in order to counteract the weak institutional capacity in the process of designing and validating local developing strategies.

Keywords: development, urban growth, spatial tools, local strategies, GIS, public authorities.
\end{abstract}

\section{Introduction}

In the context of designing small and medium cities, integrated urban development plans or local developing strategies, public authorities, local utility operators, private companies and not least, civil society can significantly improve and reshape a city's development path. Romanian policy frameworks indicate only the 
direction and basic recommendations for a short period of time and in this step for 7 years, afferent to 2014-2020 programing period. For that, adjacent results of this documents in the implementation phase must reflect a proper performance in a short period of time, quantified and evaluated by short term indicators, in the time both qualitative and quantitative. Previous experience shown that cities can change enormously within a short period of time in both direction, the worse or for the better. For a positive trend, tools used in this local plans, including input data must be consistent and validated by public institutions. That's way some small and medium cities had problematic track records for previous programing period (2007-2013).

As an aside, we should mention that there is no global definition widely accepted to understand of what is meant by term "small and medium cities". Each country defines its meaning small and medium cities, based on geographical, historical and administrative considerations (Le Gleau et al. [1]). In 2001 is developed and published Law no. 351 of 6 July 2001 on the Approval of the Spatial Planning of the National Territory - Section IV Human Settlements Network, which establishes among other things, national network settlements hierarchy and transition methodology for locality from one to another rank (for example minimum quantitative and qualitative indicators for urban and rural settlements) (Law no. 351/6 July 2001 [2]).

Urban settlements with populations under 50,000 inhabitants are included in small and medium cities category, according to the classification used by the Romanian law presented above, and they fit into Rank II (municipalities of intercounty, county importance or with a balancing role within the network of human settlements) and Rank III (cities) (see Figure 1).

In the last decade, the role of small and medium cities from Romania decreased from sustainable local development point of view, due to the fact that most of them declined in terms of socio-economic aspects. In this cases there was a low capacity of local authorities to design, develop and implement integrated urban development plans due to lack of tools tailored urban needs. This situation was reached due to the fact that employers from municipalities have insufficient professional training in urban planning, designing and implementing development strategies, as well as lack of use of functional tools and proper data. This was observed both on operational and financial departments.

\section{Data source and importance}

According to national legislation, in Romania, public authorities agreed to develop programs in order to design local development strategies and plans to improve the sustainability of local communities. The process should extensively engage local public authorities, community members, as well as the political parties whose members serve as mayors in these communities. Both field assessment and desk-analysis carried out at local level, in order to identify the potential for local development and the needs of the local communities is used for further design of the strategies, and recommendations for improving budgetary performance in particular (e.g. The Cities Alliance [4]). 


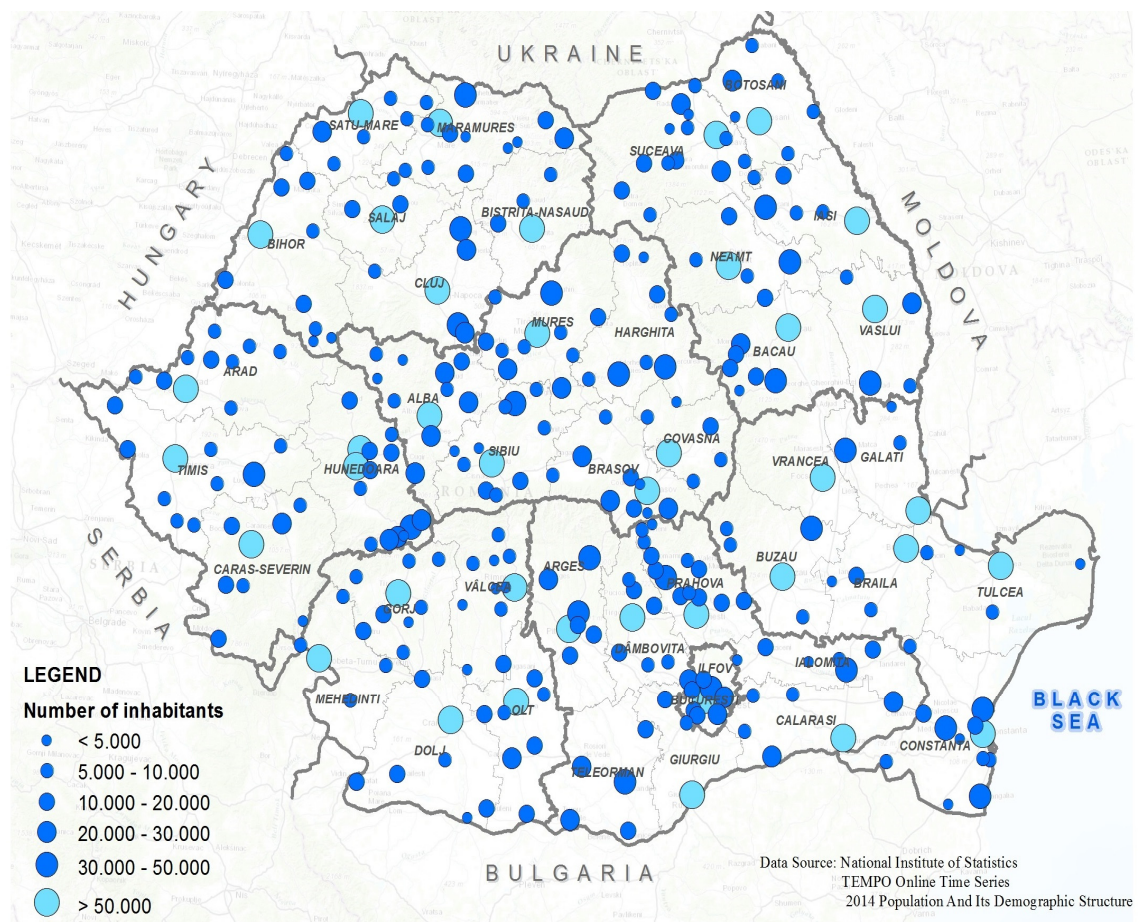

Figure 1: Cities' population distribution in Romania. Representation was made by authors, based on official data issued by the National Institute of Statistics, TEMPO database [3].

Because documents must be adapted to the local context design and implementation must follow five distinctive phase according cu use of specific data, i.e. Table 1. Furthermore in the process of implementing spatial tool, primary data that initially can be found in a static form will turn into a dynamic form, changed and improved in every phase. The process is cyclical and data will get consistency in the process validation. In some cases some data sets will be removed, or completely replaced, due to age and emergence of new datasets, i.e. Figure 2. In the first phase of data types evolution requires to understand the basic principles of solution needed to be implemented. When data is presented only as a question or is just displayed in charts or graphs, it is difficult to understand the full context of the problem (Gerull [5]).

For example, if we want to identify and represent in a punctual manner the problematic area from a periphery of a city. Analysis of graphs and diagrams that are populated with data on ownership or rental certificates, property values, sales/purchase reports, statistical processing on population issues/demands, crime rates, etc., can't provide a general overview similar to maps analysis that correlate all this information in an effective and comprehensive manner. 
Table 1: Integrated urban development plan phases and data start-up data.

\begin{tabular}{|c|c|c|}
\hline Phase & Description & Data types \\
\hline I & $\begin{array}{l}\text { An integrated urban development plan, starting off from a } \\
\text { comprehensive mapping of the communities' profiles, including } \\
\text { local statistical current data and forecasts. }\end{array}$ & $\begin{array}{l}\text { - static data } \\
\text { - dynamic data }\end{array}$ \\
\hline II & $\begin{array}{l}\text { A map including the prioritization (based on expected benefits, } \\
\text { opportunity, and other relevant criteria) of the projects included in } \\
\text { the development plan and possible funding sources (e.g. an action } \\
\text { plan, including prioritization, for the optimization of the local } \\
\text { budget planning and execution, prioritization for the attraction } \\
\text { and management of EU funds). }\end{array}$ & $\begin{array}{l}\text { - static data } \\
\text { - dynamic data } \\
\text { - validated data }\end{array}$ \\
\hline III & $\begin{array}{l}\text { A framework for the implementation, monitoring and periodical } \\
\text { evaluation of the integrated plan's implementation. }\end{array}$ & $\begin{array}{l}\text { - dynamic data } \\
\text { - validated data }\end{array}$ \\
\hline IV & $\begin{array}{l}\text { Assistance instruments for local authorities in improving their } \\
\text { budget planning and execution skills, as well as their capacity to } \\
\text { attract investors and funds, both from the EU and from other } \\
\text { sources. }\end{array}$ & $\begin{array}{l}\text { - dynamic data } \\
\text { - validated data }\end{array}$ \\
\hline $\mathrm{V}$ & Implementation documents and periodic monitoring reports. & $\begin{array}{l}\text { - dynamic data } \\
\text { - validated data }\end{array}$ \\
\hline
\end{tabular}

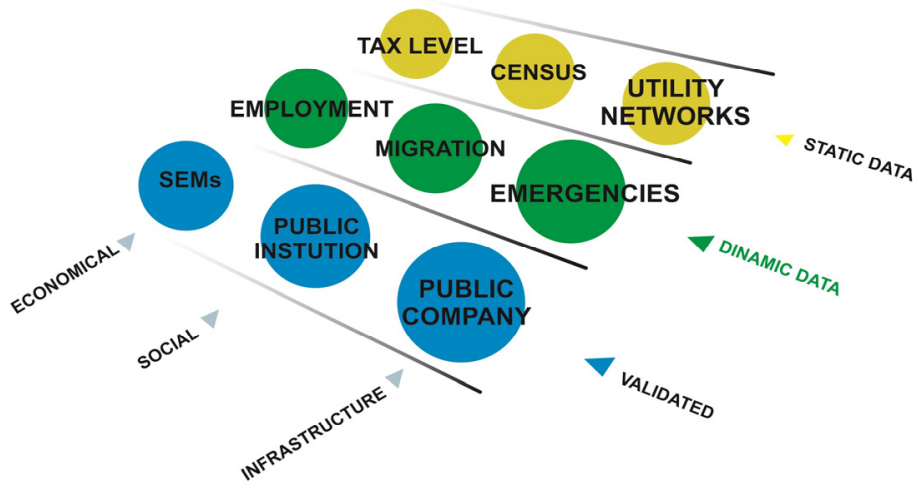

Figure 2: Data types and evolution level.

\section{Methodology}

Before designing and using a spatial tool in necessary to express in a more coherent manner the ultimate goal of the project, which is the financial and logistical implications of end users, respectively the type of application that is compatible. Also should be defined exactly which data sets can be interpreted, processed or replaced by the municipality personnel. Whether we discuss an application designed for urban planning, management services or public awareness the conditions and development trends should be followed in real time.

The methodology for development a coherent tools must include, but not be limited to the next specific elements: 
- Strategic framework analysis: identification of the EU, national, regional and county strategic directions and priorities that could be relevant for the development of integrated urban development plans;

- Stakeholders mapping: mapping of all stakeholders relevant for the design and implementation of the development plans, using proper tools. The mapping should be completed following desk studies and field visits in a spatial manner, highlighting network development both analytical and spatial using selfdeveloping links between public actors;

- Data analysis: applied desk analysis of the existing quantitative and qualitative data relevant for a development plans as well as an assessment of big-data gathered in the field. Broader regional exchanges and integration patterns for similar small and medium cities are analyzed. In the field, primary the information is collected by peer group discussions and in depth interviews which are carried out with the locals, including stakeholders and the formal and informal community leaders;

- Awareness engagement represented by organized activities that raise awareness among the members of the community on the initiatives, that engage both the inhabitants and the local authorities in the design and implementation so as to build trust and enhance the sense of ownership in the community and ensure support from the political actors. Community buy-in and engagement are paramount for the success of design and implement of local plans.

- Strategic planning: actual design of the development plan with short, medium and long term planning (including strategic directions and action plans);

- Prioritizing and matching: match concrete projects with potential funding sources in equivalent with implementation action plan;

- Budget management that offers customized solutions for improving budget performance and future budgetary exercises, for medium and long term.

In some cases, a certain situation appears such that distribution and staging above elements is not done properly. Only data analysis can lead to errors in developing a local plan. Therefore, attention is recommended throughout the lifecycle of developing a public development plan (Figure 3). Largely, various

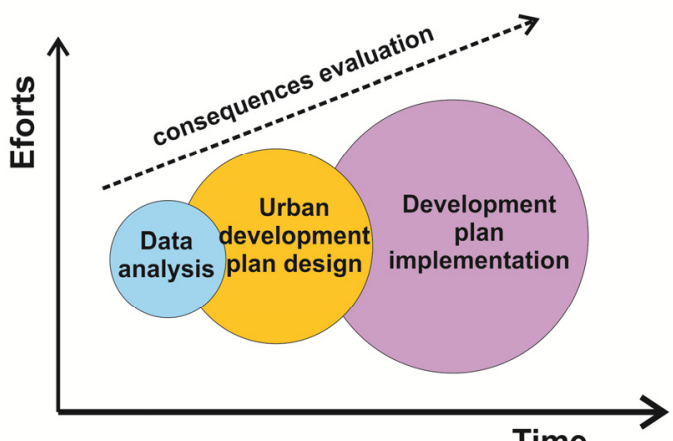

Time

Figure 3: Recommendation on developing a public development plan, adaptation after Danielson and White [6]. 
data are recorded in different forms, in records owned and maintained by various departments city council, so it is necessary to undertake organizational and technical measures to bring them into a unified form compatible with the designed plan. On the other hand, it may be noted that a number of data needed for proper operation, is missing or have incomplete attributes, therefore collection from the field is mandatory.

\section{Spatial tools development}

\subsection{Spatial tools and GIS}

A spatial tool for integrated urban development plan represents a technical ensemble that consist in specialized personnel, equipment, methodologies and regulation (internal and external) aimed to collect, storage, validate, analyze, exchange and present relevant information and data for developing local plans (Gustafson [7]). Compulsory this tool must be part of an integrated informatics system at local level.

An integrated informatics system implemented at local administration levels, generally consists in a data collection software, database management system, involving report processing and preparation, and analysis and planning solution (Petrescu [8]). To spatial relate the collected data, booth from analytical source and field interpretation, a Geographic Information System must be used (Aronoff [9]). The GIS technology facilitates the use of data no matter if we are talking about infrastructure, demographic, socio-economic or public works data. For a tool to be fully functional it must answer to basic questions in development plan process (i.e. Figure 2).

Using GIS end-user solutions to analyze information related to elements in urban areas is becoming mandatory these days, because a GIS approaches information management towards data (Huxhold [10]). Spatial solutions comprises means for including, viewing and understanding the relationship (or lack of them) between different types of data in order to produce new datasets.

Answering each of the questions given in Table 2 allows decision makers to evaluate dependencies and interdependencies of datasets relationships generated from initial datasets. This new approach also affects local governments that tend to use, represent am publish data in a more coherent way. For example, in case of sewerage network development, can be conducted without the owners agreement of private plots due to the use of cadastral plans (or ortofotmaps) that contain errors or because they are not updated. However those maps are included in the municipality database and even if are out of date and they are not representing proper in-situ characteristics, and construction permits are given based on old types of data. This type of error in some cases remain uncorrected for years, although the agency responsible assumed the data accurately that must reflect the reality on the ground (Figure 4). 
Table 2: Questions in spatial tool development.

\begin{tabular}{|l|l|}
\hline \multicolumn{1}{|c|}{ Category } & \multicolumn{1}{c|}{ Questions } \\
\hline $\begin{array}{l}\text { The institutions and } \\
\text { departments involved } \\
\text { and in charge }\end{array}$ & $\begin{array}{l}\text { Who will use the data? What decisions will be taken in } \\
\text { designing and implementation phase? }\end{array}$ \\
\hline Data and information & $\begin{array}{l}\text { What data category should be collected? Who should } \\
\text { organize data collection to avoid duplication and } \\
\text { inconsistency in them? }\end{array}$ \\
\hline Procedures & $\begin{array}{l}\text { What are the levels of analysis? What are the procedures to } \\
\text { achieve all spatial indicators? }\end{array}$ \\
\hline Technologies & $\begin{array}{l}\text { What technologies are needed to comply with the } \\
\text { procedures set? }\end{array}$ \\
\hline
\end{tabular}

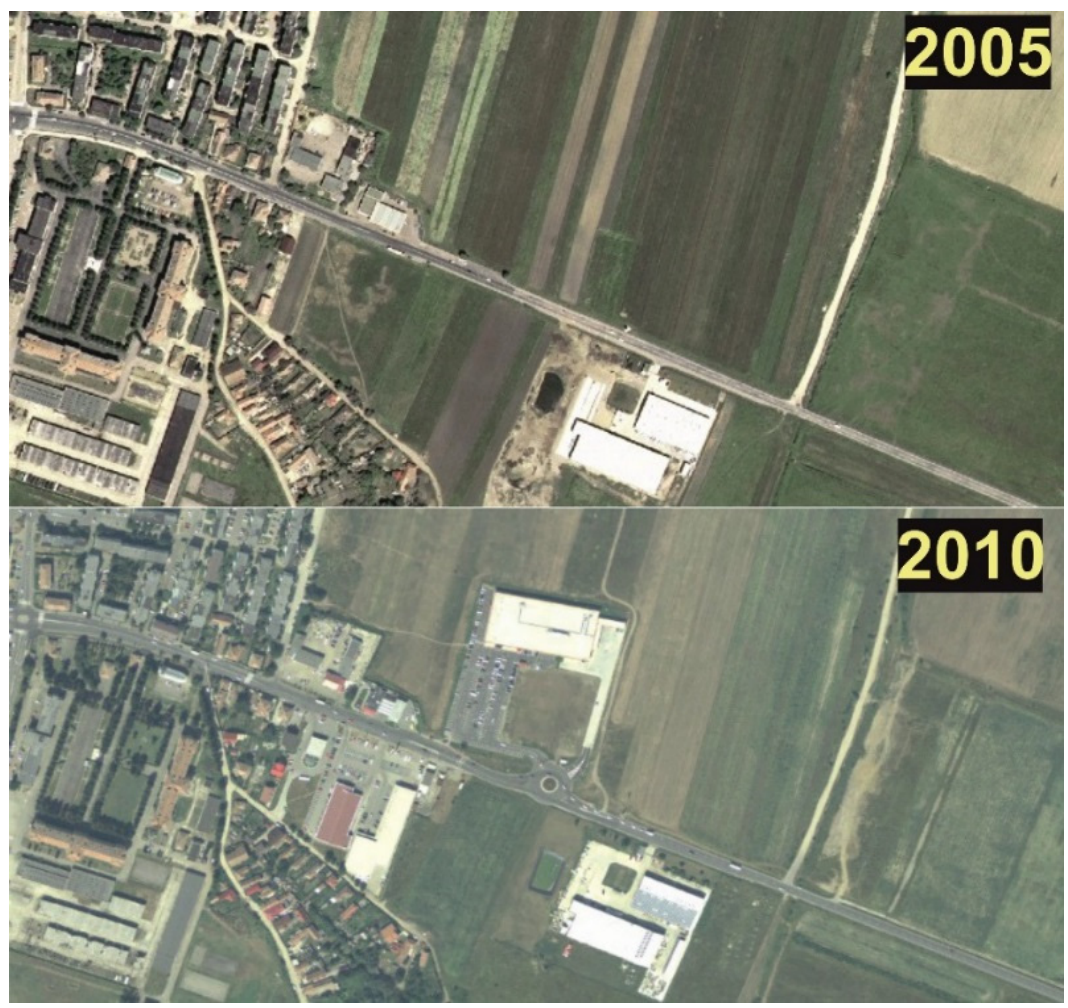

Figure 4: 2005 and 2010 ortofotomap selection from Fagaraș City. Source: National Agency for Cadastre and Land Registration [11].

\subsection{Local analysis partial results}

Analysis results from planning process based only on existing local database can be significantly improved when taking into account the results from spatial evaluation. This is the purpose of this level of analysis and conclusions obtained 
are more accurate than those conducted only on descriptive database. For several advantages we can mention selective analysis results:

- local data or estimation of occupation coefficient of the building from different classes settlement;

- high degree of expertise based on preliminary modification on buildings types with different classes of distribution;

- a detailed inventory with including costs for transport systems;

- data on construction costs and other economic parameters;

- possible emergency and break down maps;

- data summary for modeling economy characteristics of the city and surrounding area in order to predict development impact.

Gathering such data requires considerable effort but one that uses the methodology may waive some data that they consider insignificant. Also to obtain such information requires a very good collaboration between decision-makers from local authorities and especially good coordination. Also for more fundamental results separate studies can be used, for example infrastructure networks independent development (water, sewage, gas, heat, electricity, data and communication, etc.), and built fund shrinkage. This analysis requires a considerable financial effort by the local authorities but the results have a high degree of accuracy.

Access to and re-use of data results should, be unrestricted, except for information consisting of privacy data, data protected by confidentiality, and data labeled as national security information. The EU framework for access to information is clearly laid out in directive 2013/37/EU. This directive, not yet adopted yet by Romanian legislative, includes the right of access to information in machine readable form and in open formats that ensure interoperability. The cost for access to information should be free or only cover the marginal cost of supplying the information and there should be a right to reuse the information by the citizens (Directive 2013/37/EU [12]). Therefore datasets resulted from implementing process are relevant not only for technical process of developing local plan but also for the entire community, including decision making factors.

\section{Recommendations in implementation phase}

The most sensitive stage in implementing an integrated development plan is the achievement and functional future use of spatial fiscal infrastructure. After analyzing the technical documentation within the municipality in Romania is observed that service providers do not always provide a high technical documentation and coherent data, although conditionality specifications were respected (WB Report ROP 2.0 [13]). In addition, the capacity of the beneficiary represented by the local government could not successfully manage all service contracts with predefined spatial tools models.

In addition, the capacity of the beneficiary represented the local government could not successfully manage all urban analyses and services. If data contributors, analyst and designers lack the necessary resources (human, material and time) for 
developing good documentation, beneficiaries lack the capacity to receive proper spatial instruments and in some case to reject it.

To substantiate acceptance or rejection of the integrated development plans and adjacent documentation that do not comply with the technical regulations we drill the following obligations:

- Include in the form of contract proper instruments and spatial tools that need to be used as performance indicators;

- Inclusion and compliance of activities and results indicating proper terms;

- The detailed property rights on technical documentation and instruments used;

- Avoiding the selection of winners after the 'lowest price' and after the tender evaluation method technical scores, or the proportion of costs to be minimized from a specification and contract model for the auction (whether proposed tender design or tender for the design and implementation).

In terms of personnel should be provided with specific human resources (administrative, legal and financial) that can manage full and undivided all service contracts relating to implementation plan. This recommendation should not necessarily implemented directly by a municipality but can be managed through existing structures or but also by development agencies or inter-local action groups. For example specialized personnel could include in the technical audit reports the spatial analyzes, not just descriptive ones. This can lead to compliance with quality indicators and implementation of development plans, not only from financial aspects. In addition staff can perform periodic technical audits and therefore avoid errors in implementing phases or at the end programming period.

\section{Conclusions}

Any spatial tool and component database, including digital maps is valuable and can be useful only to extent that properly reflect reality on the ground. Given the dynamics of change that characterize urban areas, it is necessary to provide a maintenance system involving all the departments and institutions concerned.

A successful development of small and medium cities is influenced both by internal factors, as well as external ones. Relevant factors responsible for a potential growth are numerous, but all of them are represented in different analyses by spatial data managed by proper tools: geographic location, neighborhoods, infrastructure influence, public works developments, financing potential or human resources. Thereby taking into accounts only as principal factor population structure and evolution potential in the process of developing integrated urban development plans through spatial distribution in territory for example will conduct do false results. In addition to above factors related in fact city, small and medium cities are affected to a great extent, by the evolution of public authorities' internal procedures or internal systems used.

From new tools implementation perspective it's necessary to be not only developed but also implemented in current use procedure as an expression of its socio-economic functions whose influence extends beyond the administrative borders. 
Particular attention should be given to instruments that will lead in the future to active city attractiveness and real competitiveness. Using spatial tools the development plans should not neglect pubic action in developing investment location quality such as urban utility networks or urban streets.

Not at least, exchange of experience between cities similar cities with similar problems and opportunities must be taken into account in designing and implementing integrated urban development plans. Examples of good practices are not always available for long period of time due to the fact that in a specific point in time different events happens with specific conditions. Transferability of good practice examples is limited by local conditions and circumstances and more important by public authority personnel perception.

\section{Research context}

This paper and presented spatial tool development process is undertaken under the project "Urban Climate Study of Bucharest, Romania (UCS 2013)" developed by the scientific research project number IZERZ0_142160 within the RomanianSwiss Research Programme 2011-2016 (RSRP 2011). One of the main objectives of the project is to implement modern urban climate strategies in Romania and to analyze in detail and improve the urban climate situation of Bucharest using spatial tools. Using numerical urban climate models like ENVI-met potential urban planning scenarios will be simulated to improve urban climate, human comfort, air pollution and health (UCS Project [16]).

\section{References}

[1] Le Gleau, JP., Pumain, D., Saint-Julien T., "Villes d'Europe : à chaque pays sa définition", Économie et Statistique, no. 294-295, pp. 9-23, 1996.

[2] Law no. 351 of 6 July 2001 on the approval of The Spatial Planning of the National Territory - Section IV Human Settlements network.

[3] National Institute of Statistics <http://www.insse.ro/cms/> (25 January 2015), www.insse.ro

[4] The Cities Alliance, "Guide to City Development Strategies, Improving Urban Performance”, pp. 21-24, 2006.

[5] Gerull, L., "External services in. The GIS Guide for Local Government Officials", Ed. by Cory Fleming. International City/Country Management Association (ICMA). ESRI Press, Chapter 5, pp. 81-104, 2005.

[6] Danielson, L., White, N.," Using GIS in public policy analysis: North Carolina. Raleigh", N. C.: Design Research Laboratory, North Carolina State University, $<$ http://www.ces.ncsu.edu/depts/design/research/WECO/policyGIS/index. html> (2 December 2014), 1998-2012.

[7] Gustafson, B., "Strategies and technologies for integrated land administration and management of national resources", FIG Commission 7 Cadastre and land management, Symposium on Innovative Technology for Land Administration, Wisconsin, 24-25 June 2005. 
[8] Petrescu, F., "Sisteme informatice geografice în urbanism şi amenajarea teritoriului/Geographic Informatics Systems in Urban and Regional Planning”, ed. Matrix Rom, Chapter 2, pp. 1-14, 2007.

[9] Aronoff, S., "Geographic Information Systems: A Management Perspective", WDL Publications, Ottawa, Canada, 2000.

[10] Huxhold, W., "An Introduction to Urban Geographic Information Systems", Oxford University Press, New York, USA, 1991.

[11] National Agency for Cadastre and Land Registration, "Geoportal viewer," $<$ http://geoportal.ancpi.ro/geoportal/viewer/index.html $>$ (15 January 2015).

[12] Directive 2013/37/EU of the European Parliament and of the Council of 26 June 2013 amending Directive 2003/98/EC on The re-use of public sector information, 2013.

[13] The World Bank Report, "ROP 2.0 Facilitation of Proactive and Direct Support for Applicants and Beneficiaries of regional Operational Programme 2014-2020", Romania Regional Development Program, pp. 60-66, 2013.

[14] Romania's Territorial Development Strategy (RTDS) - Romania polycentric 2035, Territorial cohesion and competitiveness, development and equal opportunities for population, version 2, February 2015, $<$ http://www.sdtr.ro/50/Analize teritoriale $>$ (16 March 2015).

[15] ESPON 2020 Draft Program Documents, $<$ http://www.espon.eu/export/sites/default/Documents/Programme/ESPO N2020/ESPON2020Consultation/CP_PUBLIC_CONSULTATION_ESPO N_2020-V5-4-3-2014.pdf > (25 January 2015).

[16] UCS: Urban Climate Study of Bucharest, Romania, $<$ http://urbanclimate.utcb.ro> (20 march 2015).

[17] National Strategy for Sustainable Development of Romania - Horizon 2013 - 2020-2030, Ministry of the Environment and Forests, http://www.mmediu.ro/dezvoltare_durabila/strategia_nationala.htm, 2008. 